\title{
Armazenamento de variedades de bananas em condições de atmosfera modificada com permanganato de potássio
}

\section{Heloisa Alves de Sousa Falcão ${ }^{1}$, Andreia Oliveira Fonseca ${ }^{2}$, Josemar Gonçalves de Oliveira Filho $^{3}$, Marcio de Carvalho Pires ${ }^{2}$, José Ricardo Peixoto ${ }^{2}$}

\author{
${ }^{1}$ Instituto Federal de Brasília, Campus Planaltina, Planaltina, Distrito Federal, Brasil. E-mail: heloisa.falcao@ifb.edu.br \\ ${ }^{2}$ Universidade de Brasília, Brasília, Distrito Federal, Brasil. E-mail: andreia.fonseca@ agronoma.eng.br, mcpires@unb.br, \\ peixoto@unb.br \\ ${ }^{3}$ Instituto Federal Goiano, Campus Rio Verde, Rio Verde, Goiás, Brasil. E-mail: josemar.gooliver@gmail.com
}

Recebido: 04/06/2017; Aceito: 05/09/2017

\section{RESUMO}

A banana (Musa spp.) representa uma das principais frutas brasileiras com relação a produção e comercialização. Entretanto, as perdas pós-colheita têm sido bastante significativas. Assim, o presente trabalho teve por objetivo avaliar a qualidade de duas variedades de bananas armazenadas em sistema de atmosfera modificada com a utilização de absorvedor de etileno impregnado com solução de $\mathrm{KMnO}_{4}$, com e sem refrigeração. O delineamento experimental adotado foi em blocos casualizados em arranjo fatorial $2 \times 2 \times 2$ com três repetições e seis períodos de armazenamento. Avaliou-se a qualidade dos frutos quanto à perda de massa fresca, teor de sólidos solúveis (SS), acidez titulável (AT) e relação SS/AT. Os resultados indicaram que a combinação do uso da embalagem com o bloco de gesso com $\mathrm{KMnO}_{4}$ resultou no retardamento do processo de maturação dos frutos. Foi observado que os frutos submetidos a embalagem com a atmosfera modificada e com absorvedores, independente das condições de temperatura, não apresentaram perdas de massa significativa, indicando que a utilização de embalagem plástica de polipropileno é uma solução recomendada para evitar alterações no pós-colheita.

Palavras-chave: Pós-colheita, etileno, qualidade, fruta tropical.

\section{Bananas varieties of modified atmosphere storage conditions with potassium permanganate}

\begin{abstract}
The banana (Musa spp.) represents one of the main Brazilian fruits in relation to the production and commercialization. However, post-harvest losses have been quite significant. The objective of this work was to evaluate the quality of two banana varieties stored in a modified atmosphere system using ethylene absorber impregnated with $\mathrm{KMnO} 4$ solution, with and without refrigeration. The experimental design was a randomized complete block design in factorial arrangement $2 \times 2 \times 2$ with three replicates and six storage periods. Fruit quality was evaluated for fresh mass loss, soluble solids content (SS), titratable acidity (TA) and SS/TA ratio. The results indicated that the combination of the use of the package with the plaster block with $\mathrm{KMnO}_{4}$ resulted in the delay of the fruit maturation process. It was observed that the fruits submitted to packaging with the modified atmosphere and with absorbers, independent of the temperature conditions, did not present significant losses of mass, indicating that the use of polypropylene plastic packaging is a recommended solution to avoid post-harvest changes.
\end{abstract}

Key words: Post-harvest, ethylene, quality, tropical fruit. 


\section{Introdução}

A banana é uma das frutas mais consumidas no mundo; segundo a FAO (2011) em 2009, o consumo de banana por habitantes foi em média de 11 quilos. Uma das explicações pelo alto índice de consumo é o elevado valor nutricional que a fruta possui e as expressivas quantidades de carboidratos (23\%), proteínas (11\%) e lipídeos (0,3\%) (USDA, 2015).

Apesar do grande potencial de produção de alimentos, há um grande problema mundial em relação ao desperdício. Segundo dados da FAO (2013), 54\% do desperdício de alimentos no mundo ocorre na fase inicial da produção, manipulação pós-colheita e armazenagem. Os restantes $46 \%$ ocorrem nas etapas de processamento, distribuição e consumo. Percebe-se então a necessidade de aumento de pesquisas na área a fim para redução do desperdício incluindo a etapa de pós-colheita.

A banana é um fruto climatério, por isso possui um período de amadurecimento curto, o que significa menor tempo de conservação, segundo Prill et al. (2012) isso ocorre pela alta taxa respiratória e produção de etileno que a fruta possui, fator que acelera o amadurecimento; também não suporta baixas temperaturas não podendo ser armazenada a $12-13{ }^{\circ} \mathrm{C}$ mesmo com o uso de embalagens especiais as quais proveem uma atmosfera modificada (SILVA et al., 2007).

A atmosfera modificada reduz, as trocas gasosas no que se refere à respiração do produto. Os baixos níveis de $\mathrm{O}_{2}$ e a elevação de $\mathrm{CO}_{2}$ no ambiente de atmosfera modificada colaboram para a redução do efeito de $\mathrm{O}_{2}$ no metabolismo dos frutos. A diminuição de $\mathrm{O}_{2}$ age como inibidor da cadeia respiratória, pois o $\mathrm{O}_{2}$ é importante no processo oxidativo (SANTOS et al., 2006).

Para conservação de frutas e hortaliças é necessário o controle da concentração de etileno, porém, não há uma definição dos níveis que devem ser eliminados para obtenção de um resultado positivo no controle da maturação, por isso é de suma importância ter o conhecimento da concentração ideal pois quanto menor a concentração de etileno, maior deverá ser o efeito do absorvedor ou um maior período de absorção de etileno, gerando assim um maior custo de armazenamento (BRACKMANN; SAQUET, 1999). Segundo Amarante e Steffens (2009), o controle do teor de etileno e de sua ação na maturação podem ser alcançados com a colheita de frutos em estágios pré-climatérico e armazenamento em recintos com produtos removedores deste fitormônio.

Desta maneira, para prolongar o tempo de prateleira de diversas frutas e hortaliças tem-se utilizado embalagens produzidas com permanganato de potássio ou sachê de permanganato na parte interior das embalagens com a finalidade de absorver o etileno gerado pelos frutos no período do amadurecimento
(JERONIMO; KANESIRO, 2000; PFAFFENBACH et al., 2002).

A utilização de adsorvedores de etileno à base de permanganato de potássio $\left(\mathrm{KMnO}_{4}\right)$ tem sido eficiente na eliminação deste fitohormônio no armazenamento de frutas. $\mathrm{O}$ permanganato de potássio $\left(\mathrm{KMnO}_{4}\right)$ causa a oxidação do etileno, resultando em água, gás carbônico, dióxido de manganês e potássio (WILLS; WARTON, 2004; CAMPOS, et al., 2007). Estudos comprovaram que a eliminação deste gás, por meio dos absorvedores, mantém a conservação e proporciona menor perda de massa em mangabas (NASSER, et al., 2015)

O objetivo deste trabalho foi avaliar os aspectos relativos à qualidade físico-química e conservação de duas variedades de bananas quando mantidas em sistema de atmosfera modificada com a utilização de absorvedor de etileno impregnado com solução de permanganato de potássio, com e sem refrigeração.

\section{Material e Métodos}

O experimento foi conduzido no Setor de Fruticultura da Estação Experimental de Biologia EEB, Universidade de Brasília-UnB, situada em Brasília, Distrito Federal. Foram utilizadas bananas da variedade cv. Prata-Anã e cv. Grand Naine plantadas e colhidas manualmente no estádio de maturação 2 (casca verde com traços amarelos), no período de análise, na Fazenda Agua Limpa, localizada na região de Vargem Bonita.

O delineamento experimental empregado foi de blocos inteiramente casualizados, em arranjo fatorial $(2 \times 2 \times 2)$, totalizando 8 tratamentos, sendo 2 variedades de bananas, 2 temperaturas $\left(27{ }^{\circ} \mathrm{C}\right.$ e $\left.13{ }^{\circ} \mathrm{C}\right)$ e 2 condições de atmosfera (com e sem $\mathrm{KMnO}_{4}$ ), com 3 repetições das análises sendo realizadas no dia da colheita (tempo zero), 5, 10, 15, 20, 25 e 30 dias de armazenamento.

A produção dos bloquinhos consistiu na mistura de gesso e água e moldagem em formas de gelo. A solução consistiu na dissolução de $55 \mathrm{~g}$ do permanganato de potássio em $500 \mathrm{~mL}$ de água destilada; os bloquinhos de gesso foram mergulhados na solução por 30 segundos para completa absorção da solução.

As bananas foram despencadas e levadas para a sanitização inicial visando a retirada de restos florais e eliminação de látex, imersas em tanques de lavagem contendo água e detergente neutro $(0,5 \mathrm{~L}$ de detergente para $8.000 \mathrm{~L}$ de água).

As amostras foram organizadas em grupos de 3 bananas para cada tratamento, com três repetições para cada. Em cada grupo das bananas cv. Prata-Anã foram colocados apenas um bloquinho com solução de permanganato de potássio e para as bananas variedades cv. Grand Naine adicionou-se dois bloquinhos. A 
determinação da quantidade de bloquinhos foi determinada pela literatura que indicou a quantidade de sache na relação de $10 \mathrm{~g}$ para cada $500 \mathrm{~g}$ de fruto. As amostras foram colocadas nos sacos e vedados para criação da atmosfera modificada.

Para as condições de avaliação em temperatura controlada os frutos foram acondicionados em estufa DBO (TECNAL, TE391), calibrada para manutenção da temperatura de $27 \pm 0,2{ }^{\circ} \mathrm{C}$; para temperatura de refrigeração utilizou-se a câmara fria com temperatura de $13 \pm 1,0{ }^{\circ} \mathrm{C}$, com umidade relativa de 60 a $75 \%$.

As análises físico-químicas avaliadas foram: perda de massa fresca, proporção polpa/casca, teor de sólidos solúveis, acidez titulável e relação SS/AT.

A perda de massa fresca foi determinada em balança semi-analítica (URANO, US 15/5), considerando-se a diferença entre a massa inicial do fruto e aquela obtida em cada intervalo da amostragem, sendo o resultado expresso em porcentagem $(\%)$.

O teor de sólidos solúveis (SS) foi determinado por leitura em refratômetro digital (ATAGO, Pocket Palm Perform) com escala variando de 0 até $30 \%$, com compensação automática de temperatura. Para a banana verde, tomou-se $5 \mathrm{~g}$ de polpa e diluiu-se em 5,0 $\mathrm{mL}$ de água destilada, sendo posteriormente filtrado em papel filtro. Para a banana madura, após a trituração, tomou-se de duas a três gotas da amostra filtrada após homogeneização com um bastão de vidro. As leituras foram registradas com precisão de 0,1 a $25{ }^{\circ} \mathrm{C}$ (AOAC, 1992). Os resultados foram expressos em percentagem ( ${ }^{\circ}$ Brix).

A acidez total titulável, expressa em \% de ácido málico, foi determinada em duplicata utilizando-se $5,0 \mathrm{~g}$ da amostra da polpa adicionada de $100 \mathrm{~mL}$ de água destilada e três gotas de fenolftaleína alcoólica a 1,0\%. Em seguida procedeu-se a titulação com solução de $\mathrm{NaOH}$ à $0,1 \mathrm{~N}$, previamente padronizada. Os resultados foram expressos em percentagem $(\%)$ de ácido málico através da equação 1 :

$\%(\mathrm{v} / \mathrm{p})=[\mathrm{V} \times \mathrm{f} \times$ eq. $\mathrm{g}$ ácido $\mathrm{x} 100] / \mathrm{P}$

onde, $\mathrm{V}$ = volume da solução de hidróxido de sódio gasto na titulação; $\mathrm{f}=$ fator de correção da solução de hidróxido de sódio; Eq. g ácido = equivalente grama do ácido expresso que corresponde aos equivalentes gramas de $1 \mathrm{~mL}$ de $\mathrm{NaOH}$ na normalidade utilizada, no caso do ácido málico o valor foi 67,05 e $\mathrm{P}=\mathrm{g}$ ou $\mathrm{mL}$ da amostra usado na titulação.

A relação sólidos totais solúveis (SS) e acidez titulável (AT) foi determinada pelo quociente entre estes dois constituintes. Os resultados foram expressos em valores absolutos. As médias dos resultados obtidos foram agrupados pelo teste de Scott Knott ao nível de $5 \%$ de probabilidade (BANZATTO; KRONKA, 1995). Os cálculos referentes às análises estatísticas foram executados utilizando o software SISVAR (FERREIRA, 2008).

\section{Resultados e Discussão}

Verificou-se que a utilização da embalagem de polipropileno fechada cria um sistema de armazenamento com menor quantidade e contato com o oxigênio, atuando como barreira à perda de umidade para o ambiente. Um dos efeitos da modificação da atmosfera interna da embalagem parece ser também, sobre a síntese do etileno. Este regulador de crescimento desencadeia processos envolvidos no amadurecimento dos frutos, dentre eles, a elevação na taxa respiratória. Como sua síntese requer oxigênio, a diminuição dos níveis de $\mathrm{O}_{2}$ do ar atmosférico afeta a produção endógena de etileno (LANA; FINGER, 2000).

A Tabela 1 apresenta os valores médios da vida útil das variedades de banana cv. Prata Anã e cv. Grand Nine sob diferentes condições de armazenamento. Os resultados indicam que a utilização da temperatura de refrigeração a $13{ }^{\circ} \mathrm{C}$ aumenta em 10 dias o tempo de armazenamento para a variedade cv. Prata Anã (25 dias e 15 dias respectivamente) e a cv. Grand Nine (30 dias e 25 dias respectivamente). Em condições de temperatura ambiente $27^{\circ} \mathrm{C}$ e sob atmosfera modificada com os bloquinhos de gesso com permanganato de potássio observou-se aumento do tempo de armazenamento em 5 dias para as duas variedades analisadas.

Estudo realizado por Martins et al. (2007), verificou que bananas cv. Prata Anã foram armazenadas por 35 dias a temperaturas de 10 e $12^{\circ} \mathrm{C}$ sem a utilização de atmosfera modificada. Amarante e Steffens (2009) mostraram que o uso de sachês de $\mathrm{KMnO}_{4}$ sob armazenamento refrigerado retardou o amadurecimento de maçãs 'Royal Gala'. O mesmo ocorreu em temperatura ambiente, sendo que o efeito foi observado em frutos colhidos em estádios menos avançados de maturação. Silva et al. (2010) concluem que o permanganato de potássio foi eficiente como absorvedor de etileno e manteve os mamões 'Golden' verdes durante 15 dias de armazenamento a $20{ }^{\circ} \mathrm{C}$, apresentando melhor aspecto externo em relação aos frutos não tratados com o absorvedor de etileno.

Segundo Chitarra e Chitarra (2005) a perda de massa está intimamente associada à perda de água, minimizada no armazenamento sob atmosfera modificada devido ao aumento da umidade relativa no interior da embalagem, saturando a atmosfera ao redor do fruto, proporcionando a diminuição do déficit de pressão de vapor d'água em relação ao ambiente de armazenamento e minimizando a taxa de transpiração. A Tabela 2 a perda de massa fresca das variedades de banana cv. Prata Anã e cv. Grand Nine sob diferentes condições de armazenamento. 
Tabela 1. Tempo de armazenamento de duas variedades de bananas armazenadas sob condições de atmosfera modificada, com e sem refrigeração. Brasília, DF, 2015.

\begin{tabular}{lcccc}
\hline \multirow{2}{*}{ Variedades } & \multicolumn{4}{c}{ Temperatura versus Absorvedor com $\mathrm{KMnO}_{4}$} \\
\cline { 2 - 5 } & $\begin{array}{c}\text { Temperatura Ambiente } \\
27^{\circ} \mathrm{C} \text { com } \mathrm{KMnO}_{4}\end{array}$ & $\begin{array}{c}\text { Temperatura Ambiente } \\
27^{\circ} \mathrm{C} \text { sem } \mathrm{KMnO}_{4}\end{array}$ & $\begin{array}{c}\text { Temperatura Refrigerada } \\
13^{\circ} \mathrm{C} \text { com } \mathrm{KMnO}_{4}\end{array}$ & $\begin{array}{c}\text { Temperatura Refrigerada } \\
13^{\circ} \mathrm{C} \text { sem } \mathrm{KMnO}_{4}\end{array}$ \\
\hline Prata Anã & $20 \mathrm{bB}$ & $15 \mathrm{cB}$ & $30 \mathrm{aA}$ & $30 \mathrm{aA}$ \\
Grand Naine & $25 \mathrm{bA}$ & $20 \mathrm{cA}$ & $30 \mathrm{aA}$ & $30 \mathrm{aA}$ \\
\hline
\end{tabular}

*Médias seguidas pelas mesmas letras minúsculas, nas linhas e maiúsculas, nas colunas, não diferem estatisticamente, entre si, pelo teste de Scott Knott ao nível de $5 \%$ de probabilidade.

Tabela 2. Perda de massa fresca (PMF) em duas variedades de bananas armazenadas sob condições de atmosfera modificada, com e sem refrigeração. Brasília, DF, 2015.

\begin{tabular}{lcccc}
\hline \multirow{3}{*}{ Variedades } & \multicolumn{4}{c}{ Temperatura versus Absorvedor com KMnO4 } \\
\cline { 2 - 5 } & $\begin{array}{c}\text { Temperatura Ambiente } \\
27^{\circ} \mathrm{C} \text { com } \mathrm{KMnO}_{4}\end{array}$ & $\begin{array}{c}\text { Temperatura Ambiente } \\
27^{\circ} \mathrm{C} \text { sem } \mathrm{KMnO}_{4}\end{array}$ & $\begin{array}{c}\text { Temperatura Refrigerada } \\
13^{\circ} \mathrm{C} \text { com } \mathrm{KMnO}_{4}\end{array}$ & $\begin{array}{c}\text { Temperatura Refrigerada } \\
13^{\circ} \mathrm{C} \text { sem } \mathrm{KMnO}_{4}\end{array}$ \\
\hline Prata Anã & $2,5 \mathrm{aA}$ & $2,0 \mathrm{aA}$ & $1,3 \mathrm{aA}$ & $1,7 \mathrm{aA}$ \\
Grand Naine & $1,6 \mathrm{aA}$ & $1,03 \mathrm{aA}$ & $1,81 \mathrm{aA}$ & $1,50 \mathrm{aA}$ \\
\hline * Médias & & $\mathrm{aA}$ & . \\
\hline
\end{tabular}

* Médias seguidas pelas mesmas letras minúsculas, nas linhas e maiúsculas, nas colunas, não diferem estatisticamente, entre si, pelo teste de Scott Knott ao nível de $5 \%$ de probabilidade.

Com a utilização da embalagem nas condições de atmosfera modificada controlou-se a perda de massa ao longo do armazenamento, pelos resultados não foi verificada variação estatística na porcentagem de perda de massa em nenhum dos tratamentos. A perda de massa para cv. Prata Anã foi de 2,5\% aos 25 dias de armazenamento em temperatura ambiente sob condição de atmosfera modificada. Para cv. Grand Naine a maior perda de massa foi de 2,1\% também aos 25 dias de armazenamento, sob temperatura de refrigeração e ausência de atmosfera modificada. Santos et al. (2006), estudando a influência da atmosfera controlada sobre a vida pós-colheita e qualidade de banana cv. Prata-Anã, encontraram valores de $10 \%$ de perda de massa para os frutos controle e $3,5 \%$, em frutos armazenados a $12,5^{\circ} \mathrm{C}$ durante 40 dias submetidos aos tratamentos de atmosfera controlada com diferentes concentrações de oxigênio.

Não houve diferenças significativas na perda de massa fresca entre os frutos sob atmosfera modificada com e sem os absorvedores de etileno, nas condições de temperatura ambiente ou sob refrigeração. Constata-se assim, que a embalagem plástica dificulta a troca de umidade entre o ambiente e o produto, constituindo uma barreira contra a perda de umidade. Damatto Júnior et al. (2005) caracterizaram frutas de bananeira cv. Prata Anã durante 12 dias de armazenamento sem utilização de embalagens e armazenadas em condições ambientais normais (temperatura e umidade) e verificaram aumento da perda de massa ao longo dos dias de 4,25\% para $20,4 \%$, do $3^{\circ}$ dia para o $12^{\circ}$ dia, respectivamente.

Destaca-se, que as condições de atmosfera modificada criada no trabalho resultaram em uma maior qualidade no pós-colheita de frutas devido ao controle da perda de massa. Sólidos solúveis indicam a quantidade, em gramas, dos sólidos que se encontram dissolvidos no suco ou na polpa. São medidos em ${ }^{\circ}$ Brix, sendo utilizados como uma medida indireta do teor de açúcares e aumentam com a maturação por meio de processos sintéticos ou pela degradação de polissacarídeos (CHITARRA; CHITARRA, 2005).

A Tabela 3 apresenta o teor de sólidos solúveis totais das variedades de banana cv. Prata Anã e cv. Grand Nine sob diferentes condições de armazenamento. As variedades Prata Anã e Grand Naine, quando armazenadas em temperatura ambiente na presença de $\mathrm{KMnO}_{4}$ apresentaram teor de SS de 14,2 e $9,7{ }^{\circ}$ Brix e na ausência 9,6 e 9,8 ${ }^{\circ}$ Brix, respectivamente. Os frutos refrigerados da variedade cv. Prata Anã apresentaram valores de 17,2 presença de $\mathrm{KMnO}_{4}$ e 17,8 ausência e para variedade cv. Grand nine 10,4 e $12,3{ }^{\circ}$ Brix, respectivamente

Foram obtidos resultados ao final do tempo de armazenamento variando 9,6 a 17,8 ${ }^{\circ} \mathrm{Brix}$, para os frutos da banana cv. Prata Anã e de 9,7 a $12,3{ }^{\circ}$ Brix para os frutos da variedade cv. Grand Naine no grau verde inicial e grau maduro, respectivamente.

Fernandes et al. (1979) verificaram o aumento no teor de sólidos solúveis na banana cv. Prata Anã armazenada na temperatura ambiente $23^{\circ} \mathrm{C}$ a $79,5 \%$ de umidade relativa. Os valores aumentaram de $3,40^{\circ}$ Brix no estádio verde, para $26,0^{\circ}$ Brix no estádio muito maduro.

O aumento no teor de sólidos solúveis durante a maturação dos frutos ocorre, principalmente, devido à conversão de amido em açúcares (TANADA-PALMU et al., 2002). Siqueira et al. (2010), estudando a conservação pós-colheita de genótipos de bananeiras resistentes à Sigatoka Negra sob atmosfera modificada (embalados em bandejas de poliestireno expandido), 
encontraram para os frutos de banana sem embalagem armazenadas a $25{ }^{\circ} \mathrm{C}$ um acréscimo no teor de sólidos solúveis para valores próximos de $25,0{ }^{\circ}$ Brix; os tratamentos com embalagem atingiram valores em torno de 15,0 ${ }^{\circ}$ Brix, após 8 dias de armazenamento.

A Tabela 4, apresenta o teor acidez titulável das variedades de banana sob diferentes condições de armazenamento. As variedades cv. Prata Anã e cv. Grand Naine quando armazenadas em temperatura ambiente na presença de $\mathrm{KMnO}_{4}$ apresentaram valores de 0,21 e $0,15 \%$ e na ausência 0,20 e $0,14 \%$, respectivamente. Os frutos refrigerados da variedade Prata Anã apresentaram valores de 0,47 presença de $\mathrm{KMnO}_{4}$ e 0,44\% ausência; para variedade cv. Grand nine 0,17 presença de $\mathrm{KMnO}_{4}$ e $0,16 \%$ ausência.

Com relação aos valores de acidez titulável, verificou-se diferença significativa entre as variedades Prata Anã e Grand Naine, quando armazenadas sob refrigeração (Tabela 4). Os valores obtidos estão entre os valores encontrados na literatura variando de $0,17 \%$ a $0,67 \%$ para frutos de banana (DAMATTO JÚNIOR et al., 2005; PEREIRA, 2011).

$\mathrm{Na}$ temperatura ambiente os resultados de acidez $(0,17 \%)$ foram menores quando comparados com a acidez $(0,31 \%)$ dos frutos mantidos em condições de refrigeração (Tabela 2). Rinaldi et al. (2010) observaram valores de acidez titulável de $0,28 \%$ para a variedade Nanicão mantidos na temperatura ambiente e
0,49\% em refrigeração; para a variedade cv. Prata Anã foi encontrado $0,39 \%$ em condições de temperatura ambiente e $0,54 \%$ em temperatura refrigerada, no final do período de armazenamento, similar ao verificado neste trabalho.

Nos resultados de acidez nas condições de atmosfera modificada com ou sem bloquinho absorvedor de etileno não foram verificadas diferenças significativas entre os tratamentos. Ressaltando que a presença dos absorvedores não apresenta efeitos na alteração da acidez na polpa dos frutos.

A relação SS/AT é um dos parâmetros mais utilizados na avaliação da maturidade comercial de frutos, por refletir o balanço entre os açúcares e os ácidos, muito importante e desejável nos frutos; uma das formas mais utilizadas para avaliação do sabor (CHITARRA; CHITARRA, 2005).

A Tabela 5 apresenta os resultados da relação SS/AT. Os frutos das variedades cv. Prata Anã e cv. Grand Naine quando armazenadas em temperatura ambiente na presença de $\mathrm{KMnO}_{4}$ apresentaram valores de 53 e 40,2 e na ausência 26,3 e 46,7, respectivamente. $\mathrm{Na}$ condição refrigerada os frutos da variedade Prata Anã apresentaram valores de 34,0 presença de $\mathrm{KMnO}_{4} \mathrm{e}$ 38,8 na ausência; para variedade cv. Grand Nine os valores médios corresponderam a 66,9 presença de $\mathrm{KMnO}_{4}$ e 77,2 na ausência.

Tabela 3. Teor de sólidos solúveis em duas variedades de bananas armazenadas sob condições de atmosfera modificada, com e sem refrigeração. Brasília, DF, 2015.

\begin{tabular}{lcccc}
\hline \multirow{3}{*}{ Variedades } & \multicolumn{4}{c}{ Temperatura X Absorvedor com KMnO4 } \\
\cline { 2 - 5 } & Temperatura Ambiente & Temperatura Ambiente & Temperatura Refrigerada & Temperatura Refrigerada \\
& $27^{\circ} \mathrm{C}$ com $\mathrm{KMnO}_{4}$ & $27^{\circ} \mathrm{C}$ sem $\mathrm{KMnO}_{4}$ & $13^{\circ} \mathrm{C}$ com $\mathrm{KMnO}_{4}$ & $13^{\circ} \mathrm{C}$ sem $\mathrm{KMnO}_{4}$ \\
\hline Prata Anã & $14,1 \mathrm{aA}$ & $9,6 \mathrm{aA}$ & $17,2 \mathrm{aA}$ & $17,8 \mathrm{aA}$ \\
Grand Naine & $9,7 \mathrm{aA}$ & $9,8 \mathrm{aA}$ & $10,4 \mathrm{aA}$ & $12,3 \mathrm{aA}$ \\
\hline *Médias seguidas pelas mesmas letras minúsculas, nas linhas e maiúsculas, nas colunas, não diferem estatisticamente, entre si, pelo teste de Scott
\end{tabular}

Knott ao nível de $5 \%$ de probabilidade.

Tabela 4. Teor de acidez titulável em duas variedades de bananas armazenadas sob condições de atmosfera modificada, com e sem refrigeração. Brasília, DF, 2015.

\begin{tabular}{lcccc}
\hline \multirow{2}{*}{ Variedades } & \multicolumn{4}{c}{ Temperatura versus Absorvedor com KMnO4 } \\
\cline { 2 - 5 } & $\begin{array}{c}\text { Temperatura Ambiente } \\
27^{\circ} \mathrm{C} \text { com } \mathrm{KMnO}_{4}\end{array}$ & $\begin{array}{c}\text { Temperatura Ambiente } \\
27^{\circ} \mathrm{C} \text { sem } \mathrm{KMnO}_{4}\end{array}$ & $\begin{array}{c}\text { Temperatura Refrigerada } \\
13^{\circ} \mathrm{C} \text { com } \mathrm{KMnO}_{4}\end{array}$ & $\begin{array}{c}\text { Temperatura Refrigerada } \\
13^{\circ} \mathrm{C} \text { sem } \mathrm{KMnO}_{4}\end{array}$ \\
\hline Prata Anã & $0,21 \mathrm{aA}$ & $0,20 \mathrm{aA}$ & $0,47 \mathrm{bA}$ & $0,44 \mathrm{bA}$ \\
Grand Naine & $0,15 \mathrm{aA}$ & $0,14 \mathrm{aA}$ & $0,17 \mathrm{aA}$ & $0,16 \mathrm{aA}$ \\
\hline
\end{tabular}

*Médias seguidas pelas mesmas letras minúsculas, nas linhas e maiúsculas, nas colunas, não diferem estatisticamente, entre si, pelo teste de Scott Knott ao nível de $5 \%$ de probabilidade.

Tabela 5. Relação SS/AT em duas variedades de bananas armazenadas sob condições de atmosfera modificada, com e sem refrigeração. Brasília, DF, 2015.

\begin{tabular}{lcccc}
\hline \multirow{2}{*}{ Variedades } & \multicolumn{4}{c}{ Temperatura versus Absorvedor com KMnO4 } \\
\cline { 2 - 5 } & $\begin{array}{c}\text { Temperatura Ambiente } \\
27^{\circ} \mathrm{C} \text { com } \mathrm{KMnO}_{4}\end{array}$ & $\begin{array}{c}\text { Temperatura Ambiente } \\
27^{\circ} \mathrm{C} \text { sem } \mathrm{KMnO}_{4}\end{array}$ & $\begin{array}{c}\text { Temperatura Refrigerada } \\
13^{\circ} \mathrm{C} \text { com } \mathrm{KMnO}_{4}\end{array}$ & $\begin{array}{c}\text { Temperatura Refrigerada } \\
13^{\circ} \mathrm{C} \text { sem } \mathrm{KMnO}_{4}\end{array}$ \\
\hline Prata Anã & $53,0 \mathrm{aA}$ & $26,3 \mathrm{aA}$ & $34,0 \mathrm{bA}$ & $38,8 \mathrm{bA}$ \\
Grand Naine & $40,2 \mathrm{aA}$ & $46,7 \mathrm{aA}$ & $66,9 \mathrm{aA}$ & $77,2 \mathrm{aA}$ \\
\hline *Médias seguidas pelas mesmas letras minúsculas, nas linhas e maiúsculas, nas colunas, não diferem estatisticamente, entre si, pelo teste de Scott-
\end{tabular}

Knott ao nível de $5 \%$ de probabilidade. 
De acordo com os resultados obtidos não foi verificado diferença significativa entre os tratamentos armazenados em temperatura ambiente. No entanto, observou-se diferença significativa entre as variedades Prata Anã e Grand Naine, nas condições de temperatura de refrigeração a $13{ }^{\circ} \mathrm{C}$, com valores de 38,8 e 77,2 respectivamente. (Tabela 5). Rinaldi et al. (2010) avaliando a conservação pós-colheita de banana cv. Nanicão e cv. Prata observaram valores médios de ratio para a cultivar Nanicão a temperatura ambiente de 70,6 e refrigerada de 38,7; para a cv. Prata 52,3 e 37,8 para temperatura ambiente e refrigerada, respectivamente.

Cerqueira et al. (2002) observaram para o genótipo de banana cv. Nam valor da relação SS/AT de 109,21. Pereira (2011) observaram para as variedades Prata, Maçã e Nanica valores médios de 93,5, 83,8 e 91,7, respectivamente. Salles et al. (2006) observaram valores médios de 47, 83 e 62 para as cultivares Prata, Maçã e Nanica, respectivamente, no mesmo estágio de maturação.

\section{Conclusões}

A combinação do uso da embalagem plástica de polipropileno, do bloquinho de gesso com permanganato de potássio $\left(\mathrm{KMnO}_{4}\right)$ e da temperatura de refrigeração $13{ }^{\circ} \mathrm{C}$ resultou no retardamento do processo de maturação e consequente aumento do tempo de conservação dos frutos de banana prata e nanica, caracterizando-se como uma alternativa viável e econômica para criação da atmosfera modificada.

A presença dos bloquinhos absorvedores de etileno não afetou as características de qualidade dos frutos durante o período de armazenamento.

\section{Referências Bibliográficas}

AMARANTE, C. V. T.; STEFFENS, C. A. Sachês adsorvedores de etileno na pós-colheita de maçãs 'Royal Gala'. Revista Brasileira Fruticultura, Jaboticabal - SP, v. 31, n. 1, p. 71-77, 2009

AOAC. ASSOCIATION OF OFICIAL ANALYTICAL CHEMISTRAL Official methods of Analysis of the Association of Official Analytical Chemistry. 11. ed. Washington: AOAC, 1992. $1115 \mathrm{p}$.

BANZATTO, D. A.; KRONKA, S. N. Experimentação agrícola. 3. ed. Jaboticabal-SP: FUNEP, 1995. 247 p.

BEZERRA, V. S.; DIAS, J. S. A. Avaliação físico-química de frutos de bananeiras. Revista Acta Amazônica, Manaus-AM, v. 39, n. 2, p. 423-428, 2009.

CAMPOS, J. T.; HASEGAWA, P. N.; PURGATTO, E.; LAJOLO, F.; CORDENUSI, B. R. Qualidade pós colheita de nêsperas submetidas ao armazenamento sob baixa temperatura e atmosfera modificada. Ciência e Tecnologia de Alimentos, Campinas-SP, v. 27, n.2, p.787-792, 2007.

CERQUEIRA, R. C.; SILVA, S. O.; MEDINA, V. M. Características pós-colheita de frutos de genótipos de bananeira (Musa spp.) Revista Brasileira de Fruticultura, Jaboticabal-SP, v. 24, n. 3, p. 78-89, 2002.

CHITARra, M. I. F.; CHITARRA, A. B. Pós-colheita de frutos e hortaliças: fisiologia e manuseio. 2. ed. Lavras-MG: UFLA, 2005. $783 \mathrm{p}$.

DAMATTO JUNIOR, E. R.; LEONEL, S.; PEDROSO, C. J. Adubação orgânica na produção e qualidade de frutos de maracujá-doce. Revista Brasileira de Fruticultura, Jaboticabal-SP, v. 27, n. 1, p. 188-190, 2005.

FAO. FOOD AND AGRICULTURE ORGANIZATION. Desperdício de alimentos tem consequências no clima, na água, na terra e na biodiversidade. Washington: FAO, 2011. p. 156 (Nota Técnica n. 2). Disponível em: <https://www.fao.org.br/daccatb.asp>. Acesso em: 29 nov. 2015.

FAO. FOOD AND AGRICULTURE ORGANIZATION. Desperdício de alimentos tem consequências no clima, na água, na terra e na biodiversidade. Washington: FAO, 2013. p. 213 (Nota Técnica n. 1), Disponível em: <https://www.fao.org.br/daccatb.asp>. Acesso em: 29 nov. 2015.

FERNANDES, K. M.; CARVALHO, V. D.; CAL-VIDAL, J. Physical changes during ripening of silver bananas. Journal of Food Science, Chicago, v. 44, n. 1 p. 1254, 1979.

FERREIRA, D. F. Estatística multivariada. Lavras-MG: Editora Ufla, 2008. 662 p.

JERONIMO, E. M.; KANESIRO, M. A. B. Efeito da associação de armazenamento sob refrigeração e atmosfera modificada na qualidade de mangas Palmer. Revista Brasileira de Fruticultura, Jaboticabal-SP, v. 22, n. 2, p. 237-243, 2000.

LANA, M. M.; FINGER, F. L. Atmosfera modificada e controlada: aplicação na conservação de produtos hortícolas. Brasília-DF: Embrapa Comunicação para transferência de tecnologia/Embrapa Hortaliças, 2000, n. 1, 34 p.

MARTINS, R. N.; DIAS, M. S. C.; VILAS BOAS, E. V. B.; SANTOS, L. O. Armazenamento refrigerado de banana 'Prata Anã' proveniente de cachos com 16, 18 e 20 semanas. Ciência Agrotecnologia, Lavras-MG, v. 31, n. 5, p. 1423-1429, 2007.

NASSER, F. A. C. M.; BOLIANI, A. C.; NASSER, M. D.; PAGLIARINI, M. K.; MENDONÇA, V. Z. Uso de sachê de permanganato de potássio na pós-colheita de mangabas. Nativa, Sinop-MT, v. 3, n. 4, p. 246-251, 2015.

PEREIRA, V. M. O. Qualidade pós-colheita de cultivares de bananas comercializadas em pombal - pb. Revista verde de agroecologia e desenvolvimento sustentável, Pombal - PB, v. 5, n. 1, p. 49-55, 2011.

PFAFFENBACH, L. B.; CASTRO, J. V.; CARVALHO, C. R. L.; ROSSETO, C. J. Efeito da atmosfera modificada e da refrigeração na conservação pós-colheita de manga espada 
vermelha. Revista Brasileira de Fruticultura, JaboticabalSP, v. 25, n. 3, p. 410-413, 2002.

PIMENTEL, R. M. A.; GUIMARAES, F. N.; SANTOS, V. M., RESENDE, J. C. F. Qualidade pós-colheita dos genótipos de banana PA42-44 e Prata-Anã cultivados no norte de Minas Gerais. Revista Brasileira de Fruticultura, Jaboticabal-SP, v. 32, n. 2, p. 407-413, 2010.

PRILL, M. A S.; NEVES, L. C.; TOSIN, J. M.; CHAGAS, E. A. Atmosfera modificada e controle de etileno para bananas 'Prata-Anã' cultivadas na Amazônia Setentrional Brasileira. Revista Brasileira de Fruticultura, Jaboticabal-SP, v. 34, n. 4, p. 990-1003, 2012.

RINALDI, M. M.; CARMO, N. R.; SALES, R. N. Conservação pós-colheita de banana nanicão e prata. Planaltina-DF: Embrapa Cerrados, 2010. 28 p. (Boletim de pesquisa e desenvolvimento, 2)

SALlES, J. R. J.; NETO, J. A. M.; GUSMÃO, L. L. Qualidade da banana 'Pacovan' comercializada no período maio-outubro de 2003 em São Luís-MA. Revista FZVA, Recife, v. 13, n. 2, p. 190- 196, 2006.

SANTOS, C. M. S.; VILAS BOAS, E. V.; BOTREL, N.; PINHEIRO, A. C. M. Influência da Atmosfrea Controlada Sobre a Vida Pós-Colheita e Qualidade de Banana Prata-Anã. Revista Ciência e Agrotecnologia. Lavras-MG, v. 30, n. 2, p. 98-106, 2006.

SILVA, D. F. P; SALMAO, L. C.C.; CECON, P. R.; SIQUEIRA, D. L. Efeito de absorvedor de etileno na conservação de mamão "Golden", armazenado à temperatura ambiente. Revista Ceres, Viçosa-MG, v. 57, n. 6, p. 706-715, 2010.
SILVA, S. F.; DIONÍSIO, A. P.; WALDER, J. M. M. Efeitos da Radiação gama em banana "Nanica" (Musa sp., Grupo Aaa) irradiada na fase pré - climatérica. Revista Alimentação Nutrição, Araraquara-SP, v. 18, n. 3, p. 331-337, 2007.

SIQUEIRA, C. L.; RODRIGUES, M. L. M.; MIZOBUTSI, G. P.; SANTOS, P. G DOS.; MOTA, W. F DA.; MIZOBUTSI, E. H.; OLIVEIRA, G. B. Características físico-quimicas, análise sensorial e conservação de frutos de cultivares de bananeira resistentes à sigatoca-negra. Revista Ceres, ViçosaMG, v. 57, n. 5, p. 673-678, 2010.

TANADA-PALMU, P.; FAKHOURI, F. M.; GROSSO, C. R. F. Filmes biodegradáveis. Biotecnologia, Ciência e Desenvolvimento, Brasília-DF, v. 26, n. 1, p. 12-17, 2002.

USDA. UNITED STATES DEPARTAMENT OF AGRIGULTURE. National Nutrient Database. Washington: USDA, 2015. 159 p. Disponível em: http://www.nal.usda.gov/fnic/foodcomp/cgi-

bin/list_nut_edit.pl.. Acesso em: 23 nov. 2015.

WILLS, R.B.H.; WARTON, M.A. Efficacy of potassium permanganate impregnated into alumina beads to reduce atmospheric ethylene. Journal of the American Society for Horticultural Science, Alexandria, v.129, n.3, p.433- 438, maio 2004. 